Acta Technologica Agriculturae 4

Nitra, Slovaca Universitas Agriculturae Nitriae, 2020, pp. 195-200

\title{
MATHEMATICAL MODEL OF UNIFORM CEREAL CROPS SEEDING USING A DOUBLE-DISK COULTER
}

\author{
Dmytro DEREVJANKO', Ivan HOLOVACH², Volodymyr BULGAKOV²*, \\ Yevhen IHNATIEV ${ }^{3}$, Ladislav NOZDROVICKÝ ${ }^{4}$ \\ 'Zhytomyr National Agroecological University, Ukraine \\ ${ }^{2}$ National University of Life and Environmental Sciences of Ukraine \\ ${ }^{3}$ Tavria State Agrotechnological University, Ukraine \\ ${ }^{4}$ Slovak University of Agriculture in Nitra, Faculty of Engineering, Slovakia
}

\begin{abstract}
The paper provided presents a new design of two-disk wide-row coulter that ensures uniform distribution of seeds to an even bed at the furrow bottom, as well as preserving of optimal distances between the seeds. Seeds fall from the seed tube of coil sowing apparatus onto a metal distribution plate with staggeringly arranged metal pins, which distribute the seeds to furrow bottom surface in a form of separate strips. To substantiate the kinematic and constructive parameters of proposed coulter design, a mathematical model for transport of seeds along the surface of a distribution plate was developed and the Cauchy problem for a system of the second-order quasi-linear differential equations was solved by the finite difference methods using embedded software procedures in mathematical software packages (Mathcad, Maple, etc.). The finite-difference method implementation was carried out using computer software allowing the determination of coordinates of seeds and, if necessary, changing of direction of their movement by adjusting the coulter operation to improve the distribution of seeds to soil in order to reduce the injury to them, which ultimately can contribute to an increased yield. Coverage of the plate surface and distribution pins with a rubber material can also contribute to a significant reduction in seed injury during sowing.
\end{abstract}

Keywords: sowing; seeding uniformity; differential equations; finite difference methods

Nowadays, existing coulters with seed drills show several disadvantages, e.g. the two-disk narrow-row coulter produces two grooves during the sowing process that are separated by a soil hill, at the bottom of which the seeds are distributed rather densely, almost next to each other - this leads to the significant deteriorations during the germination of seedlings, postpones the formation of root systems and stalks, impairs their utilization of water, nutrients, solar energy, and prevents the formation of vegetative and reproductive organs, which results in a significant decrease in harvest yield (Gursoy and Guzel, 2010; Karaj and Muëller, 2010).

For this very reason, the development of a more advanced coulter design, which would eliminate these disadvantages (Kovalyshyn et al., 2015), is essential and the scientific substantiation of cereal sowing by such design is a very topical scientific issue.

Multiple scientist (Prisyazhnyuk, 2013; Turan et al., 2014; Turan et al., 2015; Vasylkovska et al., 2016; Pylypaka et al., 2018) have dealt with the proposition of fundamental scientific foundations for the theory of mutual influence of working surfaces of mechanisms and seeds in order to find the optimal parameters of their work.
Modern studies on the sowing uniformity are dedicated mainly to determination of this parameter on existing crops by means of modern technical means, such as RGB cameras; multispectral imagery; hyperspectral imagery; and thermal camera (Liu et al., 2017). Neugschwandtner et al. (2020) investigated the effect of sowing uniformity on weed inhibition or crop quality. Furthermore, Egli and Rucker (2012) observed and recorded the dependencies between energy necessary for seed germination, as well as seedlings uniformity under various conditions, and sowing uniformity. Recently, several researches have focused on the investigation of technical solutions for increasing the sowing uniformity of cereal crops using the seeders for continuous sowing: Maleki et al., 2006 paid attention to improvement of form and design of bobbin sowing apparatus; however, due to the considerable distance of dosing device from sowing machine, as well as reach of a long corrugated seed tube, there was observed a decrease in sowing uniformity. Additional issues also arise as a result of chaotic mutual beating of seeds with each other and with seed tube walls, and fact that seeds are not distributed to soil at constant speed, which leads to incidental injuring of seeds and their displacement from initial appropriate position. The

Contact address: Volodymyr Bulgakov, National University of Life and Environmental Sciences of Ukraine; e-mail: vbulgakov@meta.ua 
proposed design of sowing apparatus is intended for reduction of influence of mentioned negative factors and the paper presented aims to substantiate the rational design and kinematic parameters of a two-disk wide-row coulter that would ensure the uniform distribution of seeds to an even bed at the furrow bottom during sowing, optimal distances between seeds, and mitigation of injury to seeds.

\section{Material and methods}

The general design of two-disk double-row coulter with seed drill is well-known, therefore, the focus will be put on its seed tube with a two-stream distributor. However, during sowing, two grooves are formed, at the bottom of which the seeds are often nearly entirely ovelappping, which leads to mutual interference of plants during sprouting and overall negative impact on the crop.

Traditional coulter type is disadvantageous, because the sowing gear included is of open type and is manufactured in an upright position; furthermore, it lacks devices for precompaction of the furrow bottom and walls prior to planting the seeds, leading to violation of the intended uniform distribution of seeds and deterioration of the crop yield.

This paper presents a new design of coulter with wide-working width (Derevjanko et al., 2017), which ensures an even distribution of cereal seeds to the furrow bottom during sowing and optimal distances between the seeds (Fig. 1).

Double-disk wide-row coulter works as follows: it is installed on the housing [1], which is attached by a bracket [2] to the drill frame; the disk knives [3], inclined at an angle, cut the soil layer at a pre-determined depth. The disk knives [3] mounted on hubs [4] rotate freely, when the drill moves. Pawrazor [7] spreads the soil, and its lower base [8] produces a smooth furrow and compacts it. The seeds go through the seed tube [5] and are fed down to the scattering and distribution plate [9] (inclined at an angle to the horizon) with the help of distributor [6]. Since the metal rods with a rubber-coated outer surface [10] are fastened to the plate [9], the seeds slip around the rods [10] and are transported down and evenly distributed at the bottom of compacted furrow due to gravity. Subsequently, the furrow is covered with potting soil, which is then rolled up.

\section{Research methods}

For the purposes of this research, the methods of higher mathematics, theoretical mechanics, analysing the graphical dependencies, as well as software packages for the numerical calculation and mathematical modelling, were utilized.

The main emphasis was on the process of transport of seeds along the surface of rectangular distribution plate, which would ensure uniform distribution of seeds to the even

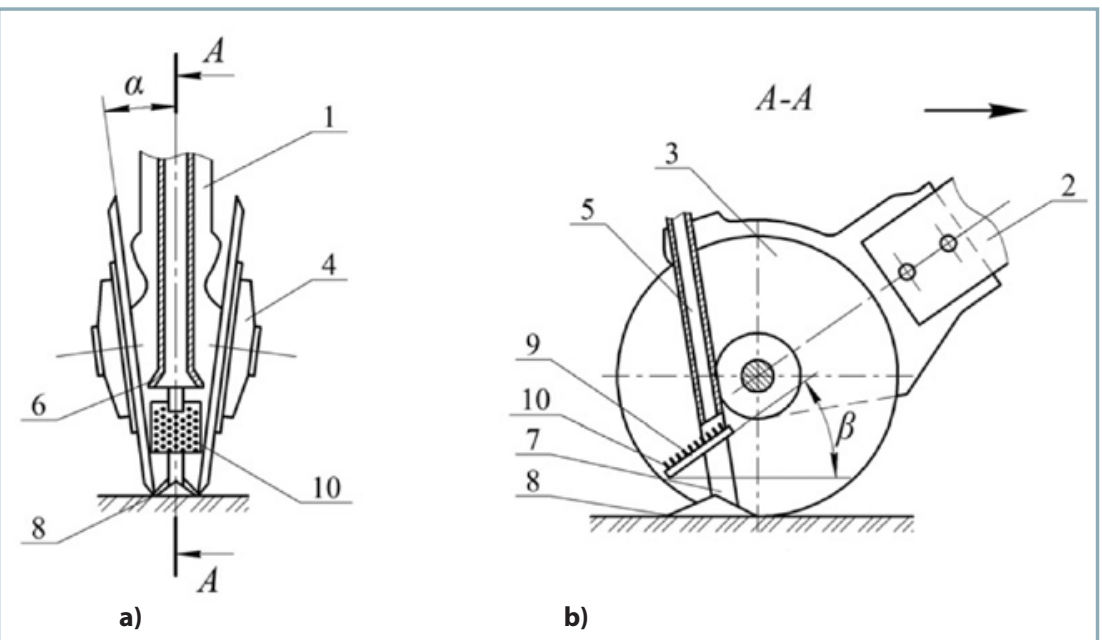

Fig. 1 Improved dual drive design of a wide-width coulter

a) front view; b) side view from the middle: 1 - case; 2 - drill frame; 3 - circular knives; 4 - hub; 5 - seed tube; 6 - distributor; 7 - paw razor; 8 - the razor paw lower base; 9 - distribution plate; 10 - pins bed at the furrow bottom formed by vomer disks (Derevjanko et al., 2017). In order to achieve this goal, it is necessary to compile the differential equations of seeds motion over the surface specified plate. However, to compile these differential equations, it is necessary to develop an equivalent force scheme for the interaction of seeds with rectangular distribution plate surface (Fig. 2).

In mathematical modelling, the mass of one seed was determined based on its geometric dimensions, the variation range of which was described by Kuzminskyi et al. (2018).

According to the received power circuit, the following forces act on individual piece of seed:

\section{Force of weight $\bar{G}$ of a seed $M$, equal to:}

$$
G=m g
$$

where:

$m$ - seed mass

$g$ - gravity force acceleration

\section{2. $\bar{N}$-normal plate surface} response.

3. Friction force $\bar{F}_{f}$, the value of which is equal to:

$$
F_{f}=f \cdot N
$$

where:

$f \quad$ - coefficient of friction

4. Force of air resistance $\bar{F}_{a}$, the value of which is determined as follows:

$$
F_{a}=k \cdot m \cdot V^{2}
$$

where:

$k$ - air drag coefficient when moving the seeds over the plate

$m$ - seed weight

$V$ - seed motion speed over the plate surface

According to the basic law of dynamics and based on the presented power scheme (Fig. 2), the seed motion equation for plate surface in vector form is:

$$
m \bar{a}=\bar{N}+\bar{F}_{f}+F_{a}+\bar{G}
$$

where:

a - movement acceleration of seeds over the plate surface 


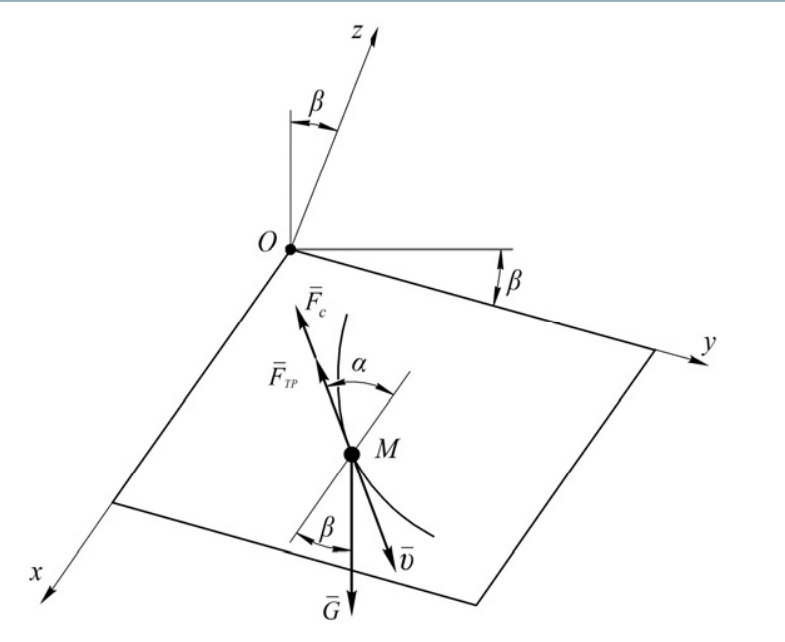

Fig. 2 Equivalent scheme of forces acting on the individual piece of seed as it moves along the distribution plate surface

Subsequently, the absolute Cartesian coordinate system $x O y z$ is selected, in which the motion of seeds under the action of forces indicated in Fig. 2 is taken into account. The axes $O x$ and $O y$ of this coordinate system are in the plate plane located at an angle $\beta$ to the horizontal plane.

Since the plate is of rectangular shape, the axes $O x$ and Oy are directed along the sides of this rectangle, as shown in Fig. 2. The axis $\mathrm{Oz}$ is directed upwards along the normal to the plate plane. As a result, the $\mathrm{Oz}$ axis forms with the vertical. Point $O$ is the origin of specified $x O y z$ coordinate system.

In terms of the Cartesian coordinate system $x O y z$, Eq. 4 has following form:

$$
\begin{gathered}
m \ddot{x}=-F_{\alpha} \cos \alpha-F_{f} \cos \alpha \\
m \ddot{y}=-F_{\alpha} \sin \alpha-F_{f} \sin \alpha+G \sin \beta \\
m \ddot{z}=N-G \cos \beta
\end{gathered}
$$

where:

$\alpha \quad$ - angle between the velocity vector $\bar{V}$ of seed on the plate plane and the axis Ox (Fig. 2)

Since this paper considers the case of continuous separation of seeds on the plate surface, its movement along the $\mathrm{Oz}$ axis will be absent, therefore, $z=0, \dot{z}=0$ and $\ddot{z}=0$. The Eq. 5 is simply an equilibrium equation, i.e. a static equation. Hence, from Eq. 5, which has following form in this case: $0=N-G \cos \beta$, one gets the value of normal reaction $N$ of plate:

$$
N=G \cos \beta
$$

Taking into account Eq. 1, there is:

$$
N=m g \cdot \cos \beta
$$

Considering the Eqs. 2, 3 and 7, Eq. 5 takes the following form:

$$
\begin{gathered}
m \ddot{x}=-m k \cdot V^{2} \cos \alpha-f m g \cdot \cos \beta \cdot \cos \alpha \\
m \ddot{y}=-m k \cdot V^{2} \sin \alpha-f m g \cdot \cos \beta \cdot \sin \alpha+m g \cdot \sin \beta
\end{gathered}
$$

Current value of the functions $\cos \alpha$ and $\sin \alpha$ can be determined from known expressions for the purposes of determination of the guiding cosines of velocity vector $\bar{V}$ through its projection on the coordinate axes:

$$
\begin{aligned}
& \cos \alpha=\frac{\dot{x}}{V}=\frac{\dot{x}}{\sqrt{\dot{x}^{2}+\dot{y}^{2}}} \\
& \sin \alpha=\frac{\dot{y}}{V}=\frac{\dot{y}}{\sqrt{\dot{x}^{2}+\dot{y}^{2}}}
\end{aligned}
$$

where:

$\dot{x}, \dot{y}$ - projections of the velocity vector $\bar{V}$ of a point (seeds in this case) on the axes $O x$ and $O y$, respectively $V=\sqrt{\dot{x}^{2}+\dot{y}^{2}}-$ velocity vector module $\bar{V}$

Substituting Eqs. 9 and 10 into Eq. 8 and reducing both sides of each equation by mass $m$, the following system of differential equations is finally achieved:

$$
\begin{gathered}
\ddot{x}=-k \dot{x} \sqrt{\dot{x}^{2}+\dot{y}^{2}}-f g \cdot \cos \beta \frac{\dot{x}}{\sqrt{\dot{x}^{2}+\dot{y}^{2}}} \\
\ddot{y}=-k \dot{y} \sqrt{\dot{x}^{2}+\dot{y}^{2}}-f g \cdot \cos \beta \frac{\dot{y}}{\sqrt{\dot{x}^{2}+\dot{y}^{2}}}+g \cdot \sin \beta
\end{gathered}
$$

If the initial conditions are added to Eq. 11, there is:

$$
x(0)=x_{0} ; y(0)=y_{0} ; \dot{x}(0)=V_{x_{0}} ; \dot{y}(0)=V_{y_{0}}
$$

Ultimately, the Cauchy problem for a system of the second-order quasilinear ordinary differential equations was achieved. The resulting problem has no analytical solution; however, it can be solved using either finitedifference analogues, or by means of procedures built in various software packages (MATHCAD, MAPLE, etc.).

Considering the further problem formulation, during the movement of seeds over the distribution plate, they meet various obstacles, due to which the direction of their movement can change. When using procedures for solving a system of differential equations in mathematical packages, such changes make it necessary to use conditional transition operators that change the solution depending on the value of the functions themselves, which makes it very difficult to build a solution algorithm.

In regard to this issue, it is the most appropriate to use the methods for solving finite-difference analogues of the second-order quasilinear ordinary differential equations proposed above. The first and second derivatives of unknown functions $x(t)$ and $y(t)$ in a certain period of time $t$ can be represented in this form:

$$
\begin{aligned}
& \dot{x}\left(t_{i}\right)=\frac{x\left(t_{i+1}\right)-x\left(t_{i}\right)}{h} \\
& \dot{y}\left(t_{i}\right)=\frac{y\left(t_{i+1}\right)-y\left(t_{i}\right)}{h}
\end{aligned}
$$

$\ddot{x}\left(t_{i}\right)=\frac{\dot{x}\left(t_{i+1}\right)-\dot{x}\left(t_{i}\right)}{h}=\frac{x\left(t_{i+2}\right)-2 x\left(t_{i+1}\right)+x\left(t_{i}\right)}{h^{2}}$ 
$\ddot{y}\left(t_{i}\right)=\frac{\dot{y}\left(t_{i+1}\right)-\dot{y}\left(t_{i}\right)}{h}=\frac{y\left(t_{i+2}\right)-2 y\left(t_{i+1}\right)+y\left(t_{i}\right)}{h^{2}}$

where:

$h \quad$ - time step (which is a fairly small period of time)

By substituting the difference analogues of derivatives into Eq. 11, where, for a more compact form of its record the following notation is used:

$$
x\left(t_{i}\right)=x_{i} ; y\left(t_{i}\right)=y_{i}
$$

In this case, the velocity modulus $V=\sqrt{\dot{x}^{2}+\dot{y}^{2}}$ takes the following form in terms of the finite-difference interpretation:

$$
\begin{gathered}
\sqrt{\dot{x}^{2}+\dot{y}^{2}}=\sqrt{\left(\frac{x_{i+1}-x_{i}}{h}\right)^{2}+\left(\frac{y_{i+1}-y_{i}}{h}\right)^{2}}= \\
=\frac{1}{h} \sqrt{\left(x_{i+1}-x_{i}\right)^{2}+\left(y_{i+1}-y_{i}\right)^{2}}
\end{gathered}
$$

Consequently, the first equation of Eq. 11 takes the following form:

$$
\begin{gathered}
\frac{x_{i+2}-2 x_{i+1}+x_{i}}{h^{2}}=-k \frac{x_{i+1}-x_{i}}{h} . \\
\cdot \frac{1}{h} \sqrt{\left(x_{i+1}-x_{i}\right)^{2}+\left(y_{i+1}-y_{i}\right)^{2}}- \\
-f g \cdot \cos \beta \cdot \frac{\frac{x_{i+1}-x_{i}}{h}}{\frac{1}{h} \sqrt{\left(x_{i+1}-x_{i}\right)^{2}+\left(y_{i+1}-y_{i}\right)^{2}}}
\end{gathered}
$$

After elementary transformations, this equation takes form as follows:

$$
\begin{aligned}
x_{i+2} & =2 x_{i+1}-x_{i}-k\left(x_{i+1}-x_{i}\right) \sqrt{\left(x_{i+1}-x_{i}\right)^{2}+\left(y_{i+1}-y_{i}\right)^{2}}- \\
& -h^{2} f g \cdot \cos \beta \cdot \frac{x_{i+1}-x_{i}}{\sqrt{\left(x_{i+1}-x_{i}\right)^{2}+\left(y_{i+1}-y_{i}\right)^{2}}}
\end{aligned}
$$

Thanks to similar transformations, the second equation of Eq. 11 takes the following form:

$$
\begin{gathered}
y_{i+2}=2 y_{i+1}-y_{i}-k\left(y_{i+1}-y_{i}\right) \sqrt{\left(x_{i+1}-x_{i}\right)^{2}+\left(y_{i+1}-y_{i}\right)^{2}}- \\
-h^{2} f g \cdot \cos \beta \cdot \frac{y_{i+1}-y_{i}}{\sqrt{\left(x_{i+1}-x_{i}\right)^{2}+\left(y_{i+1}-y_{i}\right)^{2}}}+h^{2} g \sin \beta
\end{gathered}
$$

The initial conditions of Eq. 12 can be represented as the following expressions:

$x(0)=x_{0}, y(0)=y_{0}, \dot{x}(0)=\frac{x_{1}-x_{0}}{h}=V_{x_{0}}, \dot{y}(0)=\frac{y_{1}-y_{0}}{h}=V_{y_{0}}$

or in a form, which is more convenient for calculations:

$$
x(0)=x_{0}, y(0)=y_{0}, x_{1}=x_{0}+h \cdot v_{x_{0}}, \quad y_{1}=y_{0}+h \cdot v_{y_{0}}
$$

Finally, a system of recurrent algebraic equations (Eqs. $20,21,23$ ) is obtained, which, given the known values $x_{0}, x_{1}$, $y_{0}, y_{1}$, provides an opportunity to consistently determine the coordinates of seeds on the distribution plate in each time period.

\section{Results and discussion}

The main advantage of this method is that it is possible to determine the coordinates of seed distribution at each period of movement (their discrete values depending on the step) and, if necessary, change the direction of their movement.

The solution to this problem is implemented using a developed program. For a plate with a width $a=0.075 \mathrm{~m}$ and a length $b=0.175 \mathrm{~m}$, and a selected time step $h=0.0001 \mathrm{~s}$, a cyclic procedure is constructed, which determines the trajectory of seed movement (Fig. 3).

In various situations, as a result of movement along the plate, the seeds reach its lateral boundaries; therefore, it is necessary to model the process of turning the seeds away from them.

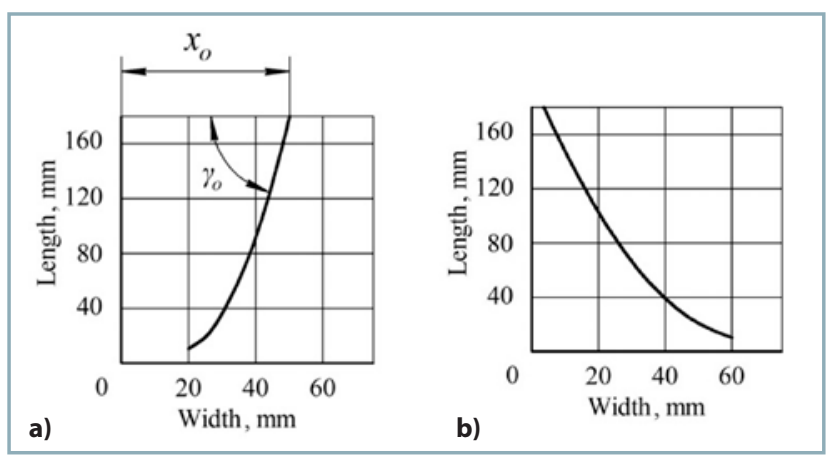

Fig. 3 Movement trajectory of seeds over the plate a) $x_{0}=50 \mathrm{~mm}, \gamma_{0}=75^{\circ}$; b) $x_{0}=4 \mathrm{~mm}, \gamma_{0}=115^{\circ}$

At the next stage, the computational algorithm is employed to determine the seed trajectory when meeting an obstacle of a cylindrical shape (Merodio and Ogden, 2019) and in a form of rubber pins on a plate with a radius $R$ centred at point $C$ with coordinates $\left(x_{c}, y_{c}\right)$.

There occur several complications in determining the further movement of seeds. In certain cases, it would be possible to apply the usual procedure of turning away the individual seeds from a fixed obstacle, but due to its ellipsoid shape, reflection may occur in an unexpected way. In this regard, it was decided to apply a probabilistic approach and, for a quantitative implementation, to use a set of random numbers to determine the direction of the initial speed of seeds after meeting the pins. This direction is determined by an angle $\gamma$ between the horizontal axis and the tangent to the pin surface of; its initial value is $\gamma_{0}$ selected randomly at the meeting point with the seeds (Fig. 4), which is determined as follows (Bocko et al., 2014):

$$
\gamma_{0}=\frac{\pi}{2}-\arctan \left|\frac{y_{c}-y_{i+2}}{x_{c}-x_{i+2}}\right|
$$

Subsequently, the value $x_{i+2}$ is changed to the value $x_{i+1}$, and the value $y_{i+2}$ is changed to the value $y_{i+1}$. 


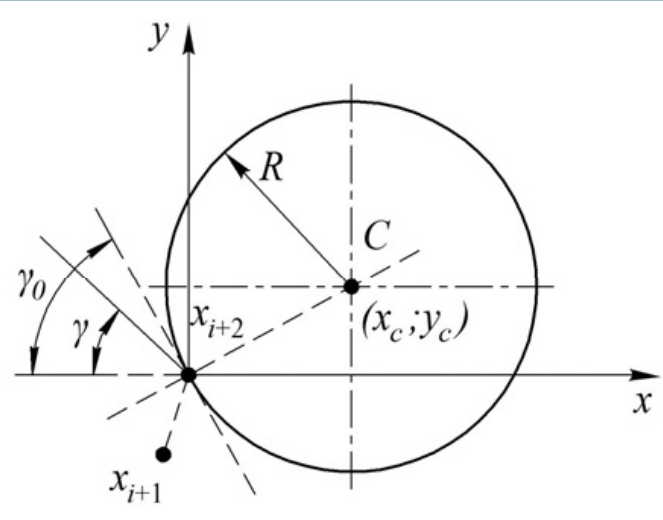

Fig. 4 Simulation of loosening the seeds from the pin

New value $y_{i+2}$ is changed to $y_{i+2}+S h \cdot \sin \gamma$, and the new value $x_{i+2}$ is changed to $x_{i+2}-S h \cdot \cos \gamma$ if $x_{i+2}<x_{C^{\prime}}$ and $x_{i+1}+$ $S h \cdot \cos \gamma$ if $x_{i+2}>x_{C}$, where $S h=\sqrt{\left(x_{i+2}-x_{i+1}\right)^{2}+\left(y_{i+2}-y_{i+1}\right)^{2}}$ (Starovoitov and Naghiyev, 2012).

The numerical implementation of algorithm for solving this problem stems from the analytical modelling of location, in which the pins act as obstacles to the movement of seeds, and step-by-step control of the coordinates of seeds that move along a distribution plate. The cyclic series of conditional operators corrects the changes in seed trajectory in case of a direct encounter with the pin, i.e. with a cylindrical barrier, or with the distribution plate lateral borders, which was considered earlier.

The final simulation stage includes determination of the optimal number of rows of pins on the distribution plate along its width and seed distribution to the soil surface.

Based on the equation of seed falling from a height $H$ and taking into account the air resistance force after its transformation and integration, as well as the accepted initial conditions, the following expression for the rate of seed fall on the distribution plate was obtained:

$$
V=\frac{3.12}{k}\left(-\sqrt{k}+\frac{\sqrt{k e^{6.24 \sqrt{k t}}}}{0.5 e^{6.24 \sqrt{k t}}+0.5}\right)
$$

where: $k$ - coefficient of air resistance to the seed movement, at $H=0.7 \mathrm{~m}, k=0.2$

Application examples of Eq. 24 and developed algorithm for determining the trajectory of seed movement are shown in Fig. 5.

The algorithm for solving this problem determines the location of the loading zone, subsequently divided into parts by a rectangular grid, from the nodes of which the initial movement of seeds and cyclical variations of initial angle of movement path occur. Numerical computer experiments showed that in order to achieve the optimal uniform distribution of seeds on the distribution plate of proposed grain drill opener, it is sufficient to place nine rows of pins on it. Both pins and distribution plate surface need to be rubber-coated in order to mitigate the injury to seeds and improve their quality indicators.

It was experimentally established that, during the fall of seeds with weight of $0.04-0.05 \mathrm{~g}$ to the distribution plate with rubber-coated pins at a height of $0.7 \mathrm{~m}$, drag and friction coefficients of $0.2-0.3$, impact force less than $5 \mathrm{~N}$, acceleration of $0.025 \mathrm{~m} \cdot \mathrm{s}^{-2}$, working body tilt angle to the soil surface of up to $30-45^{\circ}$, and an approximate value of $e \approx 2.718$, the actual movement speed of seeds will be 3.0-3.5 $\mathrm{m} \cdot \mathrm{s}^{-1}$, seed microtrauma will be close to minimum (2.5-2.9\%), and uniformity of distribution to furrow bottom after sowing will be equal to $94-95 \%$ and higher if sown in the form of strips, not rows. In such manner, there will be positive conditions for germination, growth and development of plants during the growing season, which will ensure the rational use of water, fertilizers, solar energy and formation of high and quality crops (Turan et al., 2014).

Experimental, industrial and laboratory studies on the influence of seeder working bodies on injury to seeds and their quality indicate that the largest amount of microtrauma observed during the technological process from harvest to sowing was showed by wheat variety Odesskaya-237 during threshing with the DON-1500B harvester, and the least amount of microtrauma to seeds was showed by Odessa variety 237 during threshing with a rotary combine "John Deere".

Data analyses on the quality indicators of winter wheat showed that, after sowing, the seed material purity was 98-99\%, the least amount of weeds was showed by Steppe Pearl variety, and the greatest amount of weeds was showed by Odessa-237 wheat variety -5 pieces per $\mathrm{kg}^{-1}$ of seeds.

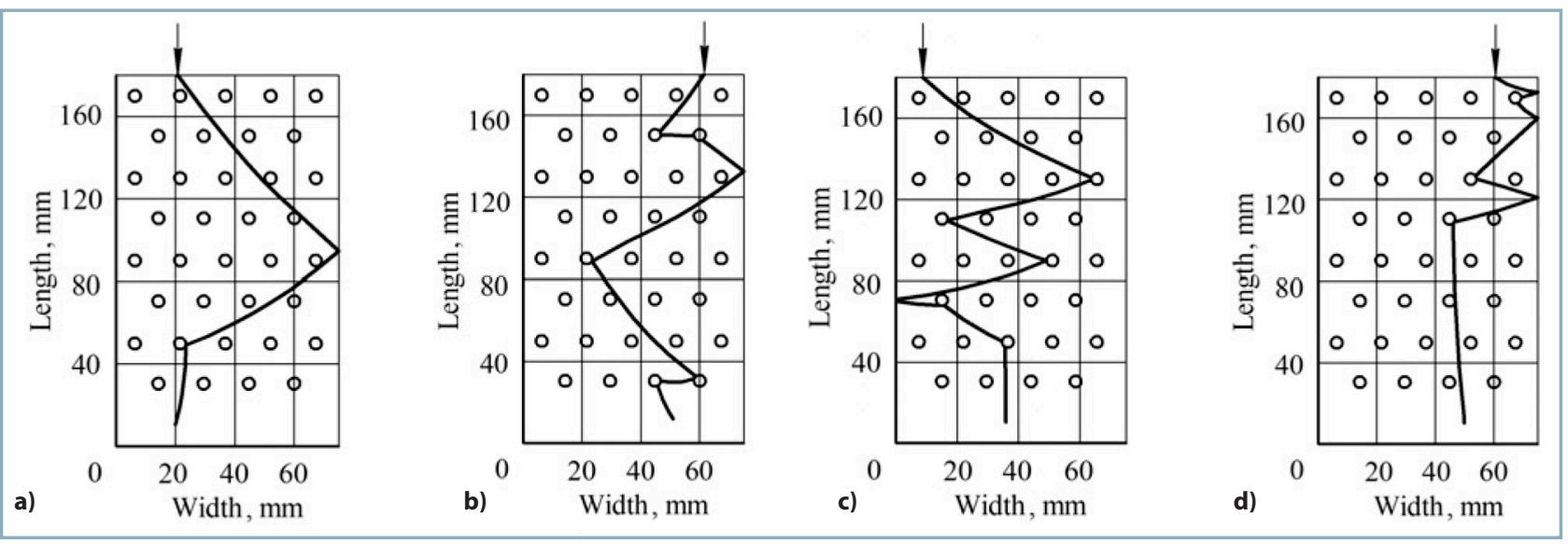

Fig. 5 Examples of the trajectory modelling of seed movement a) $x_{0}=21 \mathrm{~mm}, \gamma_{0}=130^{\circ}$; b) $x_{0}=61.5 \mathrm{~mm}, \gamma_{0}=55^{\circ}$; c) $x_{0}=9 \mathrm{~mm}, \gamma_{0}=140^{\circ}$; d) $x_{0}=60.5 \mathrm{~mm}, \gamma_{0}=155^{\circ}$ 


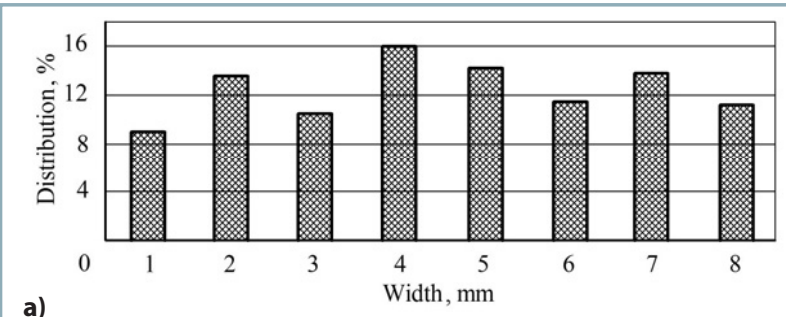

a)

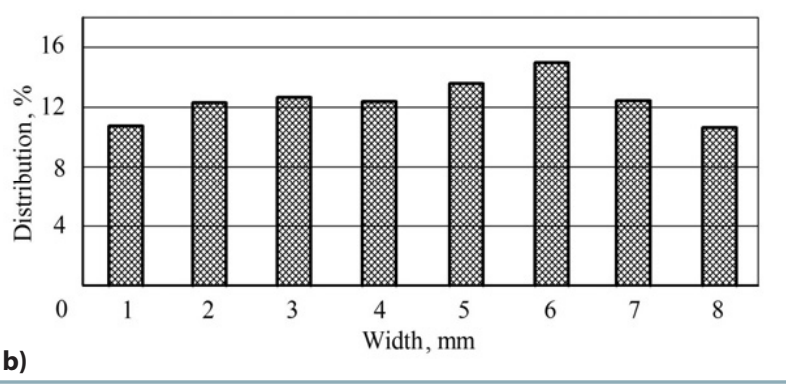

Fig. 6 Percentage values of the distribution of seeds to the furrow bottom when leaving the distribution plate along its width during sowing

a) seven rows of pins; $b$ ) nine rows of pins

It is necessary to emphasize that the bobbin machines and coulters had a negative effect on the injury to seeds and contributed to its increase by $4-5 \%$, which was the reason for the deterioration of seed quality during the sowing process - similar trend was also observed by Vasylkovska et al. (2016) and Bulgakov et al. (2016).

Similar studies on injury to seeds during sowing, conducted with respect to winter rye, showed that winter rye seeds received more significant injuries than winter wheat seeds at each stage of their treatment, including sowing. However, cultivation of this plant can be economically efficient if the seeds are uniformly distributed to the soil and the injury to seeds is minimalised as much as possible - in such manner, the plants would germinate simultaneously and each would receive the nutrition from the same zones.

\section{Conclusion}

1. A system of the second-order quasilinear differential equations was obtained, which describes the motion of seeds along the distribution plate surface.

2. Implementation of this mathematical model made it possible to determine the coordinates of seeds and, if necessary, change the direction of their movement by enhancing or modernizing the working elements of opener to improve the conditions of seed distribution to soil and reduce their injury.

3. To achieve the optimal uniform distribution of seeds on the distribution plate, it is sufficient to place nine rows of pins on it. Surface of both pins and plate must be covered with rubber material in order to reduce the injury to seeds.

4. Uniform distribution of seeds to the furrow bottom, as well as rubber coating of pins and distribution plate, contributes to reduction of seed collisions with pins along the distribution plate, mitigation of injury to seeds, germination improvement, and improve the conditions for plant growth and development, which ultimately leads to an increase in grain yield.

\section{References}

BOCKO, J. - GLODOVÁ, I. - LENGVARSKÝ P. 2014. Some differential equations of elasticity and their lie point symmetry generators. In Acta Mechanica et Automatica, vol. 8, no. 2, pp. 99-102.

BULGAKOV, V. - ADAMCHUK, V. - GOROBEY, V. - OLT, J. 2016. Theory of the oscillations of a toothed disc opener during its movement across irregularities of the soil surface. In Agronomy Research, vol. 14, no. 3, pp. 711-724.

DEREVJANKO, D. A. - GRABAR, I. G. - SINJAVSKAJA, A. I. 2017. The two-disc wide-row coulter. Patent of Ukraine №96249. (In Ukrainian: Soshnik dvuhdiskovyiy shirokoryadnyiy).

EGLI, D. B. - RUCKER, M. 2012. Seed vigor and the uniformity of emergence of corn seedlings. In Crop science, vol. 52, pp. 2774.

GURSOY, S. - GUZEL, E. 2010. Determination of physical properties of some agricultural grains. In Research Journal of Applied Sciences, Engineering and Technology, vol. 2, no. 5, pp. 492-498.

KARAJ, S. - MUËLLER, J. 2010. Determination of physical, mechanical and chemical properties of seeds and kernels of Jatropha curcas $L$. In Industrial Crops and Products, vol. 32, no. 2, pp. 129-138.

KOVALYSHYN, S. - DADAK, V. - KONYK, S. 2015. Intensification of the process of preparing small seed crop mixtures. In Acta Technologica Agriculture, vol. 18, no. 4, pp. 108-112.

KUZMINSKYI, R. - KOVALISHYN, S. - KOVALCHYK, YU. - SHEREMETA, R. 2018. Mathematical models of geometric sizes of cereal crops' seeds as dependent random variables. In Acta Technologica Agriculture vol. 18, no. 4, pp. 100-104.

LIU, T. - Li, R. - JIN, X. - DING, J. - ZHU, X. - SUN, C. - GUO, W. 2017. Evaluation of seed emergence uniformity of mechanically sown wheat with UAV RGB imagery. In Remote Sensing, vol. 9. pp. 1-15. MALEKI, M. R. - JAFARI, J. F. - RAUFAT, M. H. - MOUAZEN, A. M. BAERDEMAEKER, J. De. 2006 Evaluation of seed distribution uniformity of a multi-flight auger as a grain drill metering device. In Biosystems Engineering, vol. 94, no. 4, pp. 535-543.

MERODIO, J. - OGDEN, R. 2019. Finite deformation elasticity theory. In Constitutive Modelling of Solid Continua. Springer. doi: 10.1007/978-3-030-31547-4_2.

NEUGSCHWANDTNER, R.W. - WINKLER, J. - BERNHART, M. - PUCHER, M. A. - KLUG, M. - WERNI, C. - ADAM, E. - KAUL, H. 2020. Effect of row spacing, seeding rate and nitrogen fertilization on yield and yield components of soybean. In Die Bodenkultur: Journal of Land Management, Food and Environment, vol. 70, no. 4, pp. 221-236.

PRISYAZHNYUK, M. V. 2013. Theory of vibrating machines of agricultural production. Kiev: Agrarnaja nauka, 439 pp. (In Ukrainian: Teoriia vibratsiinykh mashyn silskohospodarskoho vyrobnytstva).

PYLYPAKA, S. F. - NESVIDOMIN, V. M. - BABKA, V. M. - KLENDIY, M. B. 2018. Particle motion on a stationary screw surface with a set axial curve. In Applied Questions of Mathematical Modeling, vol. 2, pp. 123-132. STAROVOITOV, E. I., - NAGHIYEV, F. B. 2012. Foundations of the Theory of Elasticity, Plasticity, and Viscoelasticity. New York: Apple Academic Press, $320 \mathrm{pp}$.

TURAN, J. - VIŠACKI, V. - MEHANDŽIC, S. - FINDURA, P. - BURG, P. - SEDLAR, A. 2014. Sowing quality indicators for a seed drill with overpressure. In Acta Universitatis Agriculturae et Silviculturae Mendelianae Brunensis, vol. 62, no. 6, pp. 1487-1492.

TURAN, J. - VIŠACKI, V. - SEDLAR, A. D. - PANTELIĆ, S. - FINDURA, P. - MACHAL, P. - MAREČEK, J. 2015. Seeder with different seeding apparatus in maize sowing. In Acta Universitatis Agriculturae et Silviculturae Mendelianae Brunensis, vol. 63, no. 1, pp. 137-141.

VASYLKOVSKA, K. V. - LESHCHENKO, S. M. - VASYLKOVSKYI, O. M. PETRENKO, D. I. 2016. Improvement of equipment for basic tillage and sowing as initial stage of harvest forecasting. In MATEH Agricultural Engineering. Sep.-Dec., vol. 50, no. 3, pp. 13-20. 